\title{
Acquisition of English derivational morphemes by students at selected universities in Khyber Pakhtunkhwa, Pakistan
}

\author{
Muzaffar Ali ${ }^{1}$ | Abdul Hamid*2 ${ }^{*}$ Ghani Rahman ${ }^{1}$ \\ 1. Department of English, Hazara University, Mansehra, Pakistan. \\ 2. Department of English, University of Swat, Mingora, Swat, Pakistan.
}

*Corresponding Author Emails: abdulhamid@uswat.edu.pk | abdul2016@live.com

\begin{abstract}
:
The derivational morphemes pose problems for learners of English. In this connection, the nature of the problems faced by the learners needs to be investigated. This study investigates the acquisition of English derivational morphemes by undergraduate level students. Data for the study was selected from four universities of Khyber Pakhtunkhwa (KP) including Hazara University, Islamia College University, Kohat University of Science and Technology and Swat University. The findings of the study highlight that the problems faced by learners are different in nature. Some students did not easily acquire the English derivational morphemes. Their scores were different for different derivational morphemes suggesting that they had acquired some of these morphemes easily as compared to others. Derivational morphemes such as de-adjective nominal suffixes are acquired more easily as compared to de-verbal nominals. Our first hypothesis that states that class preserving suffixes are acquired easily than class changing suffixes was approved. Furthermore, the classes preserving derivational prefixes were found to be easily acquired than class changing derivational suffixes.
\end{abstract}

Article History

Received:

December 19, 2020

Last Revised:

March 25, 2021

Accepted:

March 27, 2021

Published:

June 20, 2021

Keywords: suffixes, acquisition, derivational morpheme, de-adjective nominal, lexical categories, inflectional morpheme.

\section{How to Cite:}

Ali, M., Hamid, A., \& Rahman, G. (2021). Acquisition of English derivational morphemes by students at selected universities in Khyber Pakhtunkhwa, Pakistan. Liberal Arts and Social Sciences International Journal (LASSIJ), 5(1), 338-356. https://doi.org/10.47264/idea.lassij/5.1.22

Publisher's Note: IDEA PUBLISHERS (IDEA Journals Group) stands neutral with regard to the jurisdictional claims in the published maps and the institutional affiliations.

Copyright: () 2021 The Author(s), published by IDEA PUBLISHERS (IDEA Journals Group). This is an Open Access article published under the Creative Commons Attribution-NonCommercial 4.0 International License (http://creativecommons.org/licenses/by-nc/4.0/) 


\section{Introduction}

English derivational morphemes unlike inflectional morphemes are bound morphemes which help in deriving new English words. Derivational morphemes are studied in derivational morphology, which is the area that deals with the structure and form of words in a language. For instance, the words judgment and beautifully show the internal structure: the fragments, which compose them, are judge and ment in the first word and beauty, ful, and ly in the second word. The fragments ment, ful and $l y$ are derivational morphemes that derive new word from judge and beauty respectively. These bound morphemes are used in other word in which they serve the same functions (Yule, 2014). The bound morphemes are attached to the root of the words sometimes called base words. However, there are some restrictions on the base words where apparently, these words can go with other base words. As judgemental is a word in English but judgementalment is not. Language users create new words and understand them; genticize and impactful are the two recently introduced words that involve this level of lexical structure. The acquisition, representation and usage of this information are discussed in studying language. Many theories hold this notion that the complex words comprise of separate units that are reassembled and governed by some rules.

Modern English grammars classify English words into eight grammatical categories (Huddleston \& Pullum, 2006) on the basis of their functional, morphological, semantic or syntactic usages touching down these particular aspects of each category and a word belonging to one lexical or grammatical category cannot be replaced by a word belonging to a different lexical or grammatical category serving the intended function in the context. And if replaced, it will be either grammatically incorrect or will open new realms of thoughts semantically, deviating from the established rules and principles. For instance, in a sentence, noun will replace noun and not a verb; similarly, a verb will replace a verb not a noun. The first four categories belong to the lexical category while the remaining four categories belong to the functional categories. This classification of words is based upon the shared meaning components and similar morphosyntactic behaviour of words (Jackendoff, 1990; Levin, 1993). English morphology studies the internal structure of English these words. English words are broadly formed through inflection or word formation. Inflections in English are studied in inflectional morphology which mostly deals with the inflected forms of the same word (Verhoeven \& Carlisle, 2006). The word formation in English gives rise to new English words from the already existent root words in the form of word compounding or derivation (Rodriguez-Puente, 2020). The learners need to be aware of the basics of word formation which are affixation, the application of prefixes, suffixes and the rules of word-formation (Tahaineh, 2012). Word-formation is further classified into derivational morphology and compounds.

In this study, the focus is on derivation not compounds ${ }^{1}$. The study aims at investigating the efficiency and the usage of word-formation rules at undergraduate level. Derivation is the morphological process resulting in the formation of new words. There are seven characteristics of derivation in English (Plag, 2003). Plag (2003) further suggests that derivation can be divided further into non-affixation and affixation, and both can be further expanded into another three categories. Affixation being one of the most productive morphological processes of deriving new words (Ratih \& Gusdian, 2018). The present study focuses on derivational morphemes deriving new English words through affixation. Inside affixation, only prefixes and suffixes (derivational morphemes) are investigated ignoring infixes, as many morphologists believe that there is no in fixation in English. The common relation among these morphological processes can be explained with the help of following diagram. 
Figure 1: different morphological processes for words

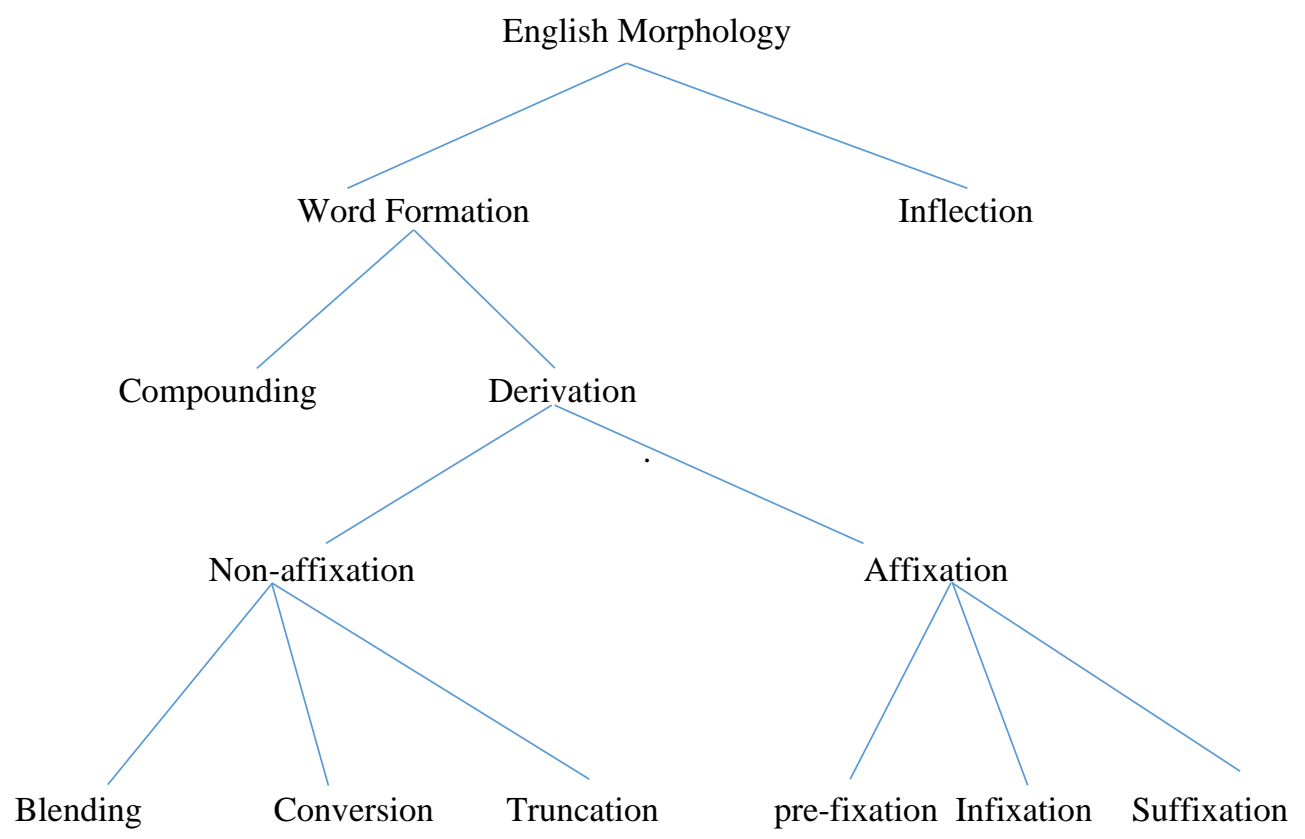

The prefix-derivation is more creative than suffix-derivation (Bizhkenova et al., 2017). Distinct characteristics of inflectional and derivational paradigms concerning productivity, semantic opacity, syntactic relevance, etc. seem to have resulted in their presenting different learning burdens for learners (Plag, 2003). Not surprisingly, native speakers commonly master inflections before derivations (Berko, 1958), as inflections are always suffixes and do not change the part of speech in word-building, while derivations include both prefixes and suffixes which frequently change the part of speech of the base word (e.g. critic-criticize, solemnsolemnity) or its meaning (e.g. care-careless, militarize-demilitarize). Inflections are differentiated from derivation with the five criteria: a) Changes in lexical meaning or parts of speech; b) Syntactic determination; c) Productivity; d) Semantic regularity; and e) Closure.

The additions of new derivational morphemes typically change the meaning of the words, while inflectional morphemes do not. Syntactic determination refers to the criterion that syntactically, inflectional morphology is separated from derivational morphology on the basis of inflectional morphology typically associated with syntax and derivational morphology not with syntax (Anderson, 1992). The new words derived through derivational morphemes fill the same slot as occupied by other members of the same grammatical category (Stump, 2001). Similarly, derivational morphemes are more productive than inflectional morphemes, i.e., the behaviour of inflectional morphemes is very predictable in the sense that if we know the grammatical category of the word, we add inflectional morpheme because the rules for adding inflections are not idiosyncratic (Halle, 1973). Semantic regularity is a property of inflectional morphemes unlike derivational morphemes (Stump, 2001). The inflectional morpheme if added to word closes the possibility of adding new derivational morpheme but derivational morpheme does allow inflectional morpheme to be used after it (Stump, 2001).

Morpheme is the smallest unit of meaning in a word (Yule, 2020). For instance, lovely is a word, which is comprised of two morphemes, i.e., love and $l y$. Further, a morpheme is further classified into two classes; a free morpheme, as laugh, make, dog etc.; or a bound morphemes 
which include -ous, -ed, -ing, -s and -un etc. (Carter, 1998). Root is considered the one which cannot be further analysed, either in terms of inflectional or derivational morphology (Bauer, 1983). Base characterizes a wide range and concept than root; base is any form of the word to which affixes are added (Bauer, 1983). In the word unacceptable, for instance, accept is the root word and unacceptable, accept and acceptable are all bases. Stem, on the other hand, refers to the concept when stem is used dealing with inflectional morphology and it is the form of the word when all the inflectional affixes (not the derivational ones) are detached (Bauer, 1983). Word is the ultimate maximal form of the root along with all derivational and inflectional morphemes attached.

Derivational morphemes (bound morphemes) deriving new words are, positionally, either prefixes or suffixes. The morphological process of prefixation and suffixation are broadly described as affixation (Yule, 2014). On linguistic point of view, English derivational morphemes are distinguished in to two classes, neutral and non - neutral suffixes. The neutral suffixes leave the words, they are detached from meaningful. Neutral suffixes are -ment, -ize, and $-e r$ for example. These suffixes have certain characteristics which make them comparatively easy to learn. They attach to words which can survive alone and meaningful when the suffixes are detached. These words are called independent words such as 'owner', when the suffix '-er' is removed from the word 'own'. The word formed from the attachment of neutral suffixes is transparently related to the stem word. The non-neutral suffixes are those which are attached to bound morphemes and if removed from the bound stem, the stem does not stand alone as an independent word. Some of the non-neutral suffixes are '-ive, -ic, -ous, ian, -ify, and -ity'. The non-neutral suffixes, if removed from the bound stem, the stem does not remain a meaningful word. For instance, if '-ify' is removed from 'quantify', or the word 'qualify', the word 'qual-' does not remain a word in the true sense. Further, non-neutral suffixes cause change of stress and the quality of vowel in the stem when they are added to the words. This change can be reflected in the pronunciation of ' $a$ ' such as 'Divine-Divinity'. The words that are formed originally made from non-neutral suffixes are not transparently related such as 'carnation', 'carnivore' and 'carnival'. Both the types of suffixes have a difference in their applicability. Neutral suffixes have a great scope and area in terms of applicability. For instance, the non-neutral suffix '-er' can make agentive when they are attached to verb such as 'blow - blower' while non-neutral suffixes have not such kind of applicability and thus do not capture or cover that much area or aspects. Kiparsky (1982) notes those words, which are formed from particular root morpheme receiving non-neutral suffixes. For instance, the root word '-ceive' will take '-tion', 'receive-reception, deceive-deception, conceive-conception, perceive-perception'. Quite the same, the root '-fer' will take '-ence' as 'infer-inference, refer-reference', prefer-preference'. Although there are some idiosyncratic exceptions within this pattern of paradigm. The words such as arrive/arrival/arrivation*, derive/derival*/derivation, deprive/deprival*/deprivation and starve/starical*/starvation is exploring and studying the different dynamics and characteristics of neutral and non-neutral suffixes, one would believe.

Similarly, derivational morphemes could be class maintaining and class changing morphemes. Class maintaining derivational morphemes are morphemes like the bound morpheme ' $r e$ ' when used with a free morpheme does not change the class of the root word but just change the meaning of the word. For example, the word open and reopen both are verbs but have different meaning. Class changing derivational morphemes are the bound morphemes that change the class of the root word, for example when we add the bound morpheme 'ment' with the verb develop, we get the noun development. 


\subsection{English grammatical categories and derivational morphemes}

New words in English are derived with the help of English derivational morphemes. These derivational morphemes can derive new nouns, verbs, adjectives and adverbs. The newly derived words sometimes have the same lexical class and sometimes a different class from the root word. The attachment of particular derivational morpheme with a particular English root word (free morpheme) is always arbitrary. In most of the cases, we cannot predict the compatibility of a derivational morpheme with particular word, and in the case of second language learning, under the effect of L1 structures among so many other factors could bring awareness about derivational and inflectional morphemes (Vidra \& Zabokrtsk'y, 2017). Therefore, the best way to derive new words from the already existing root words is to know about each individual root word and the derivational possibility for it to make a new word ${ }^{2}$. In this regard, Gardner (2007) notices that derivations are learned later than inflections.

There are certain derivational morphemes (mostly in the form of suffixes) like 'ment, ness, tion, ty, ship' etc. which are only attached to nouns (Huddleston, 1985). The suffixes deriving English nouns are attached to different lexical categories. For example, the suffixes -al, -age, -ation, -ancy, -ance, -ee, -ency, -er /or, -ment derive nouns from verbs. There are other derivational morphemes (suffixes) like -al, -ee, -ess, -er, -ette, -ing, -hood, -ism, ology, -ocracy, -phile, phobe, -phobia, -ship, -ist that derive noun from other nouns. There are other derivational morphemes in the form of suffixes like -al, -ance, -ency, -ence, -ness, -ity, that derive noun from adjectives. In similar fashion, prefixes also derive nouns. But mostly the prefixes deriving nouns derive noun from already exiting nouns. For example, the derivational morphemes in the form of prefixes like the prefixes ante-, anti-, bi-, cent(i)-, co-, counter-, cyber-, dis-, e-, eco-,euro-, ex-, fore-, geo-, hyper-, kilo-, mal-, mega-, micro-, mid-, milli-, mini-, mis-, mono-, neo-, non-, out-, photo-, poly-, pre-, pro-, psycho-, re-, semi-, sub-, super, tele-, thermos-, tri-, ultra-, uni-, and vice- when attached with other nouns derive nouns.

There are a few derivational morphemes (suffixes) that derive the lexical category of verb. For example, the suffixes, -ate, -ify, and -ise/-ize derive verbs from nouns, while the suffixes en, ise/-ize derive verbs from adjectives. . In similar fashion, prefixes also derive verbs. Some of the prefixes like ante-, counter-, de-, fore-, inter-, mal- and dis-, mis-, over-, re-, under-, trans, un- out- derive verbs from other verbs. While the prefix en- derives verb from noun. Similarly, the suffixes-ful, -al, -ed, -like, -less, -ly, -centric, -ish, -y, -proof, -(i)an, -ical, -ous, and -ic, derive adjectives from noun. While the suffixes -able, -ed, -ive, and -ous, derive adjectives from verbs. The suffixes -ish, and -ward derive adjectives from other adjectives. The prefixes a-, Anglo-, mal-, micro-, mono-, multi-, over-, neo-, non-, omni-, ir-, inter-, il-, im-, poly-, trans-, semi-, socio-, pseudo-, pro-, psycho-, pre-, hyper-, photo-, pan-, in-, ill-, thermos-, ultra, tri-, tele-, eco-, super-, sub-, geo-, counter-, ante-, euro-, dis-, extra-, post-, un-, uni-, anti-, auto-, and bi- derive adjectives from other adjectives. While a few prefixes like super- and telederive adjectives from nouns. The suffixes $-\mathrm{ly}$, and -ward(s), derive adverbs from adjective while the suffix -wise derive adverbs form the noun. The only prefix that derives adverbs from nouns is $a$-.

\subsection{Purpose of the study}

Derivational affixes/morphemes are part of morphological analysis. It is essential for the students to know about derivational affixes/morphemes. The students can derive a lot of parts of speech from a single word when they are able to recognize derivational morphemes. If the 
students have not enough knowledge of vocabulary, then Mastering English is very difficult task for them. Derivational morphemes are especially important to derive new content words (noun, verb, adjective and adverb). This research aims to find out the derivational morphemes to derive the above content words. The undergraduate level students studying English for more than sixteen years, still face problems in the correct identification of derivational morphemes, as a consequence, face problems in the correct use of the English derived words though derivation. If the students know how to derive a particular lexical category by using the appropriate derivational morphemes, their English proficiency improves, and they are successful learners. The students particularly, face problems in the derivation of particular lexical categories, which is an important aspect of morphology, lexicology and syntax. The present study tried to find out those problems for Undergraduate Level Students in Khyber Pakhtunkhwa. The study suggests some teaching measure to cope with those problems in the light of the findings of the present study. Very little overt instructions, on English derivational morphology are imparted to learners in our institutions, although its contribution cannot be denied in derived forms of English through derivation. The prime target of this study was to explore whether the learners were able to know and recognize the existence of derived form in a base context (and vice versa) which leaves a sentence grammatically incorrect and to decide this (in)ability gives forth the picture about their knowledge of derivational morphology.

\section{Literature Review}

The internal structure of words with its related knowledge plays a vital role and may lead to lexical access (Fowler et al., 1985; Stanners et al., 1979; Taft \& Forster, 1975). The derivational suffixes brand words for part of speech and refer it to different word classes. It also helps the speaker to form an idea and understanding (Clark \& Clark, 1977). It also helps by giving meaning to different derivatives (Dowty, 1978; Jackendoff, 1075; Nagy \& Anderson, 1984 ) and thus making smooth the pace of vocabulary growth. The newly derived words are enlisted in the dictionaries, but no dictionary can list all possible derived words (Berg, 2020). One of the ways to improve vocabulary is through word formation processes (Diasti, \& Bram, 2020), derivation being the most commonly used way ignoring the figurative language being a word formation process (Dimaculangan \& Gustilo, 2018).

The previous works establish this notion that neutral suffixes are easy to be acquired and picked at early stage while non-neutral are not. Dale and O'Rourke (1974) revealed that most of students knew neutral suffixes more properly than non-neutral suffixes. Sterling's (1982) looked for the ability in terms of suffixes usage and the formation of context - oriented new forms. A clear contrast was found in their dealings with neutral and non-neutral suffixes. Condry (1979) and Miller \& Gildea (1987) reported that those young children were taking help from morphology to supplement their knowledge and learned new words. They were focusing more on agentive word '-er'. Neutral suffixes are acquired at a very early stage, like pre-school days by some children. On the contrary, they have no ample understanding of processing nonneutral suffixes. Condry (1979) revealed that the students of third grade were more used to words they were familiar with, the words such as 'argue - argument'. Freyd and Baron (1982) noted their proof in children looking at semantic relationships. It may indicate that the speakers prefer using morphological knowledge with derivatives from well-known words.

Sterling (1982) found out that contextually appropriate new forms were reflecting the contribution in syntax of stems, the knowledge of morphology being multifaceted, sometime a test prepared for judging one aspect of the learner about morphology, misses out another aspect, 
the knowledge which the participants already possess. In fact, three aspects should be explored upon finding the full knowledge of derivational morphology. These three aspects are distributional, syntactic and semantic knowledge. Some of the empirical studies suggest that derivations and inflections are processed differently within a computational system. Studies on patients with severe brain damage reveal that inflections proper use is more affected than derivations and morphological processes (Laudanna et al., 1989). The morphological knowledge can lead to better linguistic performance like reading comprehension (Zhang, 2017). All English words cannot be taught, therefore, morphological processes like derivation in teaching and learning become significant for a number of reasons like increasing their vocabulary on the basis of already learned words and generalizing the already learnt lexical items' morphological markers (Shchuklina et al., 2016).

\section{Research Methodology}

The present study is descriptive and qualitative study where the researchers tried to find out problems in the deriving new words by using the derivational morphemes to be attached to the roots. The study selected fifty-two suffixes to derive English words, which included twenty seven suffixes for deriving nouns, four suffixes for deriving verbs, eighteen suffixes for deriving adjectives and three suffixes for deriving adverbs. The study also selected eighty-two prefixes for derive English words, which included thirty nine prefixes for deriving nouns, twenty seven prefixes deriving verbs, six prefixes for deriving adjectives and ten prefixes for deriving adverbs.

The data for the present study was selected from four universities of Khyber Pakhtunkhwa (KP), i.e., Hazara University, Islamia College University, Kohat University of Science and Technology and Swat University. Twenty participants from each university having equal number of male and female were selected through convenience non-random sampling. The data for this study was collected through the instrument of a proficiency test consisting of closed ended questions. The test consisted of questions about derivational morphemes. These questions were about derivational morphemes that are used to derive nouns, verbs, adjective and adverbs. The questions in the test were asked in such a way to make sure the elicitation of the derivation of the target new derived English words with the help of the derivation morphemes. The collected data was statistically analysed and the correct and incorrect percentages for each derivational morpheme were calculated establishing the knowledge level of the students about the English derivational morphemes.

\section{Results and Analysis}

The instrument of test was designed in such a way to make sure whether English undergraduate level students had acquired the selected derivational morphemes or not. Different types of questions were asked in the test to make sure the correct use of the target derivational morphemes. The percentage of correct responses about the derivation of nouns, verbs, adjectives and adverbs was calculated. The test had easy questions where the students were asked to derive new nouns with the help of the above derivational morphemes. The derivational morphemes in the form of suffixes (class changing) derive nouns from verbs and adjective. A total of twenty-seven suffixes deriving nouns were selected in the present study. Some of these suffixes are class preserving suffixes while some are class changing suffixes. The following table shows the result of the selected suffixes to derive nouns from the lexical category of verb, noun and adjective. 
The table- 1 shows $60 \%$ correct responses, which means that the students had not fully acquired the derivational suffixes deriving nouns from the lexical category of verb completely. This percentage was different for different derivational morphemes, though. This percentage was for the correct percentage $(75.08 \%)$ for nouns derived from other nouns, showing that the students had not completely acquired all these suffixes. This percentage was even less for nouns derived from adjectives (55.5\% correct responses). The results as a whole suggest that the students had not acquired completely the suffixes deriving nouns but the derivation of nouns from other nouns was comparatively easy for them than easy than derivation of nouns from verbs and adjectives.

Table-1: Suffixes deriving nouns

\begin{tabular}{lll}
\hline Bound Morpheme & Correct Use \% & Incorrect Use \% \\
\hline Deriving nouns from verbs & $60 \%$ & $40 \%$ \\
Deriving nouns from nouns & $75.08 \%$ & $24.91 \%$ \\
Deriving nouns from adjectives & $55.5 \%$ & $44.5 \%$ \\
\hline
\end{tabular}

Prefixes are class preserving derivational morphemes and so nouns derive other nouns through prefixation. Prefixes cannot derive nouns from verb and adjectives. Thirty-nine mostly commonly used prefixes were selected to derive nouns through affixation. The table- 2 shows that undergraduate level students had not fully acquired (with $65.5 \%$ correct responses) the derivational prefixes deriving nouns from other nouns. This percentage was less than the percentage for suffixes deriving nouns from other nouns. The results of the study suggest that acquisition of prefixes deriving nouns is comparatively less than the acquisition of suffixes deriving nouns.

Table-2: Prefixes deriving nouns from nouns

\begin{tabular}{lll}
\hline Bound Morpheme & Correct Use \% & Incorrect Use \% \\
\hline Deriving nouns from nouns & $65.5 \%$ & $34.5 \%$ \\
\hline
\end{tabular}

It was hypothesized in the study that class preserving suffixes are easier for second language learners of English than class changing suffixes. Further, it was also hypothesized that class preserving affixes are too easier than class changing suffixes. The table-3 shows that classes preserving derivational suffixes are acquired more than class changing derivational suffixes. The correct use of the class preserving derivational suffixes $(75.08 \%)$ is greater than the correct use of class changing derivational suffixes $(58.70 \%)$. The findings show that although students have problems in the derivation of nouns with the help of suffixes, but they have got more problems in the correct use of class changing suffixes than in the correct use of class preserving suffixes. The findings of the present study confirm the hypothesis of the researchers for this study that the English class changing suffixes are difficult to acquire than English class preserving suffixes.

Table-3: Overall percentage of class preserving and class changing derivational suffixes

\begin{tabular}{llll}
\hline Class Preserving & Derivational Suffixes & Class Changing & Derivational Suffixes \\
\hline Correct use $\%$ & Incorrect use $\%$ & Correct use $\%$ & Incorrect use $\%$ \\
$75.08 \%$ & $24.91 \%$ & $58.70 \%$ & $41.29 \%$ \\
\hline
\end{tabular}

The table- 4 shows that classes changing derivational suffixes are acquired more than class preserving derivational affixes. The correct use of the class preserving derivational affixes 
$(65.5 \%)$ is greater than the correct use of class changing derivational suffixes $(58.70 \%)$. The findings show that although students have problems in the derivation of nouns with the help of affixes, but they have got more problems in the correct use of class changing suffixes than in the correct use of class preserving affixes. The findings of the study confirm the hypothesis of the study that the English class changing suffixes are difficult to acquire than the English class preserving affixes.

Table-4: Overall percentage of class preserving prefixes and class changing derivational suffixes

\begin{tabular}{llll}
\hline Class Preserving & Derivational Prefixes & Class Changing & Derivational Suffixes \\
\hline Correct use $\%$ & Incorrect use $\%$ & Correct use $\%$ & Incorrect use $\%$ \\
$65.5 \%$ & $34.5 \%$ & $58.70 \%$ & $41.29 \%$ \\
\hline
\end{tabular}

Bound morphemes derive verbs from nouns, adjectives and other verbs. Unlike suffixes in the case of deriving nouns, verbs are mostly derived through prefixes. Similarly, prefixes deriving verbs could be both class preserving and class changing derivational morphemes. A total of twenty-seven affixes deriving verbs were selected in the present study. The students had not acquired fully the derivational suffixes deriving verbs from the lexical categories of nouns and adjectives. The overall percentage of correct responses was $55.25 \%$ which shows that they had not enough knowledge of English derivational suffixes deriving verbs from nouns and adjectives. The results of the above derivational morphemes as whole suggest that undergraduate level students had not acquired the above English derivational morphemes to derive verbs form nouns and adjectives.

Table-5: Suffixes deriving verbs from nouns and adjectives

\begin{tabular}{lll}
\hline Bound Morpheme & Correct Use \% & Incorrect Use \% \\
\hline $\begin{array}{l}\text { Deriving nouns from } \\
\text { nouns/adjectives }\end{array}$ & $55.25 \%$ & $44.75 \%$ \\
\hline
\end{tabular}

Verbs are derived through prefixation from nouns, adjectives and other verbs. The Ten most commonly used prefixes were selected to derive verbs through prefixation from nouns along with twelve affixes deriving verbs from other verbs and one derivational affix deriving verb from adjective. The acquisition of prefixes was difficult for students than the acquisition of suffixes. The students had not acquired almost all the derivational prefixes deriving verbs from nouns. The overall percentage of correct responses was $40.5 \%$ which shows that they had not enough knowledge of English derivational prefixes deriving verbs from other nouns. Similarly, the students had not acquired the derivational prefixes deriving verbs from other verbs. The overall percentage of correct responses was 55\% which shows that they had not enough knowledge of English derivational prefixes deriving verbs from other verbs. The percentage of correct responses was even low for derivational prefix deriving verbs from adjectives $(34 \%)$ suggesting that the derivational prefixes are more difficult for students.

Table-6: Prefixes deriving verbs

\begin{tabular}{lll}
\hline Bound Morpheme & Correct Use \% & Incorrect Use \% \\
\hline Deriving verbs from nouns & $40.5 \%$ & $595(59.5 \%)$ \\
Deriving verbs from other verbs & $55 \%$ & $539(45 \%)$ \\
Deriving verbs from adjectives & $34 \%$ & $66(66 \%)$ \\
\hline
\end{tabular}

The English prefixes are both class changing and class preserving derivational affixes deriving 
verbs from these three-word classes, while suffixes are only class changing derivational morphemes. It was hypothesized that class-preserving prefixes are easier for second language learners of English than class changing suffixes. The table-7 shows that classes preserving derivational prefixes are acquired more than class changing derivational prefixes. The correct use of class preserving derivational prefixes $(55 \%)$ is greater than the correct use of class changing derivational prefixes $(40 \%)$. The findings show that although the undergraduate level students have problems in the derivation of verbs with the help of prefixes, but they have got more problems in the correct use of class changing prefixes than in the correct use of class preserving prefixes.

Table-7: Overall percentage of class preserving and class changing derivational prefixes

\begin{tabular}{llll}
\hline Class Preserving & Derivational Prefixes & Class Changing & Derivational Prefixes \\
\hline Correct use $\%$ & Incorrect use $\%$ & Correct use $\%$ & Incorrect use $\%$ \\
$55 \%$ & $45 \%$ & $40 \%$ & $60 \%$ \\
\hline
\end{tabular}

English adjectives are the members of the only lexical category which are derived through affixation, from all the three lexical categories. A total of eighteen derivational suffixes were selected in the study. The above table shows that students had not fully acquired the derivational suffixes deriving adjectives from the lexical category of noun. The overall percentage of correct responses was $52.6 \%$, which shows that they had not enough knowledge of English derivational suffixes deriving adjectives from nouns. Interestingly, one of these suffixes was quite easy for students, while some suffixes were somewhat difficult, and some other suffixes were even quite difficult for them. On the contrary, the suffixes deriving adjectives from verbs are easier (73\%) to learn except a single morpheme. The results above show that the suffixes deriving adjectives from verbs are easy to learn except a single morpheme. The above table shows that the only suffix deriving adjective from other adjective ' $l y$ ' was highly problematic for undergraduate level students. The incorrect responses (76\%) of the students show that this suffix was not acquired by students. The reasons for this might be the use of derivational suffix ' $l y$ ' for deriving English adverbs.

Table-8: Suffixes deriving adjective from noun

\begin{tabular}{lll}
\hline Bound Morpheme & Correct Use \% & Incorrect Use \% \\
\hline Deriving adjectives from nouns & $52.6 \%$ & $852(47.4 \%)$ \\
Deriving adjectives from verbs & $73 \%$ & $107(27 \%)$ \\
Deriving adjectives from other adjectives & $24 \%$ & $76(76 \%)$ \\
\hline
\end{tabular}

The derivational morphemes in the form of prefixes are used to derive the English adjectives from nouns, adjectives and other verbs. The prefixes to derive adjectives are class changing derivational morphemes. Six most commonly used prefixes to derive adjectives form nouns, along with two prefixes deriving adjectives from verb and thirty-nine prefixes deriving adjectives from other adjectives. The following table shows the results. The table-9 shows that the prefixes deriving adjectives from the nouns are problematic for the students. The correct percentage $(50.7 \%)$ of responses show that the students have not acquired affixes completely. The prefixes deriving adjectives from verbs were even more problematic for the students. The overall low correct percentage $(30.5 \%)$ shows that the students could not derive adjectives from verbs with the help of these prefixes. The results for adjectives derived from other adjectives were a bit more than these two (57\% correct responses) but still were not significant enough. The results suggest that the students have not acquired English prefixes deriving adjectives. 
Table-9: Prefixes deriving adjectives

\begin{tabular}{lll}
\hline Bound Morpheme & Correct Use \% & Incorrect Use \% \\
\hline Deriving adjectives from nouns & $50.7 \%$ & $296(49.3 \%)$ \\
Deriving adjectives from verbs & $30.5 \%$ & $139(69.5)$ \\
Deriving adjectives from other adjectives & $57 \%$ & $1691(43 \%)$ \\
\hline
\end{tabular}

The English derivational suffixes are both class preserving and class changing suffixes. Class changing prefixes were assumed to be difficult than class changing suffixes. The above table shows that class preserving suffixes were acquired more than class changing suffixes by students. The correct responses of the class preserving suffixes had $(24 \%)$ were very low compared to the correct responses of class changing suffixes (69\%). The results suggest that if suffixes are attached to other adjectives, their acquisition become difficult and if they are attached to verbs or nouns, their acquisition becomes easier. The results of the study reject the hypothesis that class changing suffixes are difficult than class preserving suffixes for undergraduate level students.

Table-10: Overall percentage of class preserving and class changing derivational suffixes

\begin{tabular}{llll}
\hline Class Preserving & Derivational Suffixes & Class Changing & Derivational Suffixes \\
\hline Correct use $\%$ & Incorrect use $\%$ & Correct use $\%$ & Incorrect use $\%$ \\
$24 \%$ & $76 \%$ & $69 \%$ & $31 \%$ \\
\hline
\end{tabular}

English prefixes are both class changing and class preserving derivational prefixes deriving adjectives from other three-word classes. It was hypothesized that class preserving prefixes are easier to learn for second language learners of English than class changing suffixes. The table11 shows that the correct use of derivational prefixes deriving adjectives from other adjectives (class preserving derivational prefixes) was more correct than the use of the derivational prefixes deriving adjectives from verbs and nouns (class changing prefixes). The correct responses for class preserving prefixes $(57 \%)$ were a bit better than the correct responses of the class changing prefixes $(55.85 \%)$. The difference though is not great but the hypothesis that class preserving prefixes are learned easily than class changing prefixes is confirmed by the findings of the study.

Table-11: Overall percentage of class preserving and class changing derivational prefixes

\begin{tabular}{llll}
\hline Class Preserving & Derivational Prefixes & Class Changing & Derivational Prefixes \\
\hline Correct use $\%$ & Incorrect use $\%$ & Correct use $\%$ & Incorrect use \% \\
$57 \%$ & $43 \%$ & $55.85 \%$ & $40 \%$ \\
\hline
\end{tabular}

Adverbs are also derived through derivational suffixes and affixes mostly from adjectives. Three most commonly used suffixes were used to derive adverbs from other words. One of the suffixes (-ly) derive adverbs from adjective, while, the other two suffixes (-ward, -wise) derive adverbs from both nouns and adjective. The above table shows that suffixes deriving adverbs are somewhat difficult for students. There were ten derivational prefixes deriving adverbs. Most of these prefixes excluding ( $-a)$ derive adverbs from other adverbs.

Table-12: Suffixes deriving adverbs from adjectives

\begin{tabular}{lll}
\hline Bound Morpheme & Correct Use \% & Incorrect Use \% \\
\hline $\begin{array}{l}\text { Deriving adverbs from } \\
\text { adjectives }\end{array}$ & $64.3 \%$ & $35.7 \%$ \\
\hline
\end{tabular}


The results in table-13 with $62 \%$ correct responses suggest that students likewise have not acquired the prefixes deriving adverbs from other adverbs. The results of all the derivation morphemes, as a whole suggest that students have not acquired most of the derivational morphemes and these derivational morphemes should be given due importance in terms of teaching and learning opportunities.

Table-13: Showing prefixes deriving adverbs

\begin{tabular}{lll}
\hline Bound Morpheme & Correct Use \% & Incorrect Use \% \\
\hline $\begin{array}{l}\text { Prefixes deriving adverbs from } \\
\text { other adverbs }\end{array}$ & $62.4 \%$ & $37.6 \%$ \\
\hline
\end{tabular}

\section{Discussion and findings}

The correct responses in the tables suggest that students had not acquired all English derivational morphemes. Their scores were different for different derivational morphemes suggesting that they had acquired some of them but not others. Similarly, their scores were also different about different types of derivational morphemes, however, if they are attached to different lexical categories (like verb, nouns, adjectives and adverbs). The derivation through suffixation was comparatively easy for students than derivation through prefixation. Both suffixes and prefixes behaved differently with different lexical words. The derivation of nouns from other nouns through suffixation was the easiest for students than derivation of adjectives from verbs, which in turn was easier than derivation of adverbs from adjectives, and lastly, it was easier than derivation of nouns from verbs. The derivation of adjectives from adjectives through suffixation was the least acquired, followed by the derivation of adjective from noun, which in turn was easier than the acquisition of the derivation of verbs from nouns/adjectives, and lastly, the derivation of nouns from adjective was comparatively easy.

Similarly, the derivation of most lexical categories through prefixation like the derivation of nouns from other nouns was acquired more by students than the derivation of adverbs from other adverbs, which in turn was acquired more than the derivation of adjectives from other adjectives and verbs' derivation from other verbs. The difficulty for students increases if lexical categories are changed in prefixation, for example, the derivation of adjectives from nouns, which is acquired a bit more than the derivation of verbs from nouns. The derivation of adjectives from verbs and the derivation of verbs from adjectives were the least acquired through prefixation.

The derivation of the words from similarly category (class preserving) was comparatively acquired more than the derivation of words from other categories (class changing). The findings confirmed our first hypothesis that class preserving suffixes are acquired more than class changing suffixes. The class preserving suffixes are easily acquired because they do not change the grammatical status of the lexical categories (no new grammatical categories are derived) but only the lexical meaning of the new derived words is changed which are quite predictable from the meaning of the derivational suffixes themselves. Some of these derivational suffixes give just the opposite meaning of the existing words which are easier to learn. The class changing derivational suffixes, on the other hand, were difficult because they changed the grammatical status of the lexical categories (new grammatical category of words are derived) along with the change in lexical meaning of the new derived words, which are not easily predictable from the meaning of the derivational suffixes themselves. 
In other words, class changing suffixes have grammatical meaning while class preserving suffixes have lexical meaning in nature; that is why learning lexical meanings are easier than learning grammatical meanings of derivational morphemes. In morphological terms, class changing suffixes have more grammatical meaning and so, are very much like bound morphemes; while class preserving suffixes have more lexical meaning and so, are very much like free morphemes. As for grammatical morphemes, their grammatical nature must be learnt and so, are difficult for learning while, lexical morphemes are easy to learn in the sense that they have no grammatical meaning to them but only lexical meaning.

Similarly, our second hypothesis was also confirmed that classes preserving derivational prefixes were acquired more than class changing derivational suffixes because class-preserving prefixes like class preserving suffixes do not change the grammatical status of the lexical categories. Class preserving prefixes derive words from already existing ones mostly showing some properties of words which are easily learnt because these properties are mostly related to some external concepts like making diminutive of the words or changing the gender, making agentive, giving a meaning of plurality and making negative of words and these meanings are learnt which are mostly inherent in the meaning of the derivational affixes attached to the root word. The attachment of the derivation as a prefix further helps the learners to learn its meaning because of its being processed before the processing of the root word; while suffix is attached at the end of the root, which is processed later than the root word. If both suffixes and prefixes are class-changing affixes, in case of verbs derivation, the suffixes are acquired more than prefixes. This low level of acquisition is because of the reason that derivational prefixes like sometimes unlike other prefixes have no clear lexical meaning and so, students found them difficult, and they were more like bound morphemes than free morphemes.

Classes preserving derivational prefixes were acquired more than class changing derivational prefixes. The difference though was not great but the hypothesis that class preserving prefixes are acquired more than class changing prefixes was confirmed by the findings of the present study. The results suggest that if suffixes are attached to other adjectives, their acquisition become difficult and if they are attached to verbs or nouns, their acquisition becomes easier. The results reject the hypothesis that class changing suffixes are difficult than class preserving suffixes for undergraduate level students. The results also show that prefixes making the negative of the words were easily acquired because of the semantic reversal of the words' meaning. The results of all the derivation morphemes, as a whole, suggest that students have not acquired most of the derivational morphemes and these derivational morphemes should be given due importance in terms of teaching and learning opportunities.

\section{Conclusion}

The study investigated the acquisition of English derivational morphemes by undergraduate level students in selected universities. The results of test conducted about English derivational morphemes suggest that students had not acquired all English derivational morphemes. Their scores were different for different derivational morphemes suggesting that they had acquired some of these morphemes at the cost of others. Similarly, their scores were also different about different types of derivational morphemes on the one hand, and if they are attached to different lexical categories like verb, nouns, adjectives and adverbs, on the other hand. Both suffixes and prefixes behaved differently with different lexical words. The derivation of nouns from other nouns through suffixation was the easiest for students than derivation of adjectives from 
verbs, which in turn was easier than derivation of adverbs from adjectives, and lastly, it was easier than derivation of nouns from verbs.

The derivation of adjectives from adjectives through suffixation was the least acquired, followed by the derivation of adjective from noun, which in turn was easier than the acquisition of the derivation of verbs from nouns/adjectives, and lastly, the derivation of nouns from adjective was comparatively easy. Similarly, the derivation of most lexical categories through prefixation like the derivation of nouns from other nouns was acquired more by students than the derivation of adverbs from other adverbs, which in turn was acquired more than the derivation of adjectives from other adjectives and verbs' derivation from other verbs. The difficulty for students increases if lexical categories are changed in prefixation, for example, the derivation of adjectives from nouns, which is acquired a bit more than the derivation of verbs from nouns. The derivation of adjectives from verbs and the derivation of verbs from adjectives were the least acquired through prefixation.

The derivation of the words from similarly category (class preserving) was comparatively acquired more than the derivation of words from other categories (class changing). The findings confirmed that class-preserving suffixes are acquired more than class changing suffixes. Similarly, the findings also confirmed that classes preserving derivational prefixes were acquired more than class changing derivational suffixes because class-preserving prefixes like class preserving suffixes do not change the grammatical status of the lexical categories. Class preserving prefixes derive words from already existing ones mostly showing some properties of words, which are easily learnt because these properties are mostly related to some external concepts like making diminutive of the words or changing the gender, making agentive, giving a meaning of plurality and making negative of words and these meanings are learnt which are mostly inherent in the meaning of the derivational affixes attached to the root word. The attachment of the derivation as a prefix further helps the learners to learn its meaning because of its being processed before the processing of the root word; while suffix is attached at the end of the root, which is processed later than the root word.

If both suffixes and prefixes are class changing affixes, in case of verbs derivation, the suffixes are acquired more than prefixes. This low level of acquisition is because of the reason that derivational prefixes like sometimes unlike other prefixes have no clear lexical meaning and so, students found them difficult, and they were more like bound morphemes than free morphemes. If suffixes are attached to other adjectives, their acquisition become difficult and if they are attached to verbs or nouns, their acquisition becomes easier. Classes preserving derivational prefixes were acquired more than class changing derivational prefixes, the difference though was not great here. The results showed that class-changing suffixes are easier for students than class preserving suffixes, unexpectedly. The results also show that prefixes making the negative of the words were easily acquired because of the semantic reversal of the words' meaning. The results of all the derivation morphemes, as a whole, suggest that students have not acquired most of the derivational morphemes and these derivational morphemes should be given due importance in terms of teaching and learning opportunities.

\section{Implications and suggestions}

The study has many implications for teaching and learning English derivational morphemes. The findings in the study suggest that there are many problems in the acquisition of English derivational morphemes for undergraduate level students. In spite of many years of learning 
English language (morphology), the students at undergraduate level still have many problems with many derivational morphemes investigated in the present study. In the light of the present study, these problematic derivational morphemes use should be given proper attention on the part of the teachers and students. The syllabus designers should include all these derivational morphemes when they design courses about morphology. Some of these derivational morphemes are so important that they should never be ignored and must be included in every course of English morphology. We should not take for granted some of these derivational morphemes and they should be given proper attention.

The findings of the study have many implications in this regard by highlighting these problems and suggesting the remedial measures for them. The study has implications in the lights of the results of the study that they encourage learners from the standpoint of applied classroom research because they indicate that L2 learners have much to gain from learning about derivational morphology within an ESL classroom. In this connection, ESL materials developers and teaching professionals should be aware of the importance of derivational morphology in the development of L2 vocabulary knowledge. On the other hand, materials developers need to consider integrating information on derivational morphology more fully into ESL textbooks and ESL teaching professionals need to more fully integrate the teaching of derivational morphology into their ESL classrooms.

\section{References}

Anderson, S. R. (1992). A morphous morphology. Cambridge University.

Bauer, L. (1983). English word formation. Cambridge University.

Berg, K. (2020). Changes in the productivity of word-formation patterns: Some methodological remarks. Linguistics, 58(4), 1117-1150. https://doi.org/10.1515/ling-2020-0148

Berko, J. (1958). The child's learning of English morphology. Word, 14, 150-177. https://doi.org/10.1080/00437956.1958.11659661

Bizhkenova, A. E., Sultanbekova, S., \& Koshekova, A. (2017). Neologisms in present-day German: Investigation into productivity of word formation types. Journal of Fundamental and Applied Sciences, 9(7), 982-996. http://dx.doi.org/10.4314/jfas.v9i7s.89

Clark, H., \& Clark, E. (1977). Psychology and language: An introduction to psycholinguistics. Harcourt, Brace \& Jovanovich.

Condry, S. (1979). A developmental study of processes of word derivation in elementary school. Unpublished doctoral dissertation. Cornell University.

Dale, E., \& O'Rourke, J. (1974). Towards a science of vocabulary development. Mouton.

Diasti, K. S., \& Bram, B. (2020). Investigating students' familiarity with conversion, an English word formation process. Elt Echo: The Journal of English Language Teaching in Foreign Language Context, 5(1), 14-21. https://syekhnurjati.ac.id/jurnal/index.php/eltecho/article/view/6320/pdf_40

Dimaculangan, N., and Gustilo, L. (2018). A closer look at Philippine English word-formation frameworks. Article in Advanced Science Letters, 24(11), 8384-8388. https://doi.org/10.1166/asl.2018.12569

Dowty, D. (1978). Applying Montague's views on linguistics. In D. Farkas, K. Jakobsen, and K. Todrys (Eds.), Parassession on the lexicon (pp. 97-138). Chicago Linguistic Society. 
Fowler, C., Napps, S., \& Feldman, L. (1985). Relations among regular and irregular morphologically related words in the lexicon as revealed by repetition priming. Memory and Cognition, 13(3), 241-255. https://doi.org/10.3758/BF03197687

Freyd, P., \& Baron, J. (1982). Individual differences in acquisition of derivational morphology. Journal of Verbal Learning and Verbal Behaviour, 21(3), 310-332. https://doi.org/10.1016/S00225371(82)90615-6

Gardner, D. (2007). Validating the construct of word in applied corpus-based vocabulary research: A critical survey. Applied Linguistics, 28(2), 241-265. https://doi.org/10.1093/applin/amm010

Halle, M. (1973). Prolegomena to a theory of word formation. Linguistic Inquiry, 4(1), 3-16. http://www.jstor.org/stable/4177749

Huddleston, R., \& Pullum, G. (2005). The Cambridge grammar of the English language. Zeitschrift für Anglistik und Amerikanistik, 53(2), 193-194. https://doi.org/10.1515/zaa-2005-0209

Jackendoff, R. (1975). Morphological and semantic regularities in the lexicon. Language, 51, 639-671. https://doi.org/10.2307/412891

Kiparsky, P. (1982). Word formation and the lexicon. In F. Ingemann, (Ed.) Proceedings of the 1982 MidAmerica Linguistics Conference, 3-29. University of Kansas.

Laudanna, A., Badecker, W., \& Caramazza, A. (1989). Priming homographic stems. Journal of Memory and Language,28(5), 531-546. https://doi.org/10.1016/0749$\underline{\text { 596X(89)90011-9 }}$

Levin, B. (1993). English verb classes and alternations: A preliminary investigation. University of Chicago.

Miller, G. A., \& Gildea, P. M. (1987). How children learn words. Scientific American, 257(3), 94-99. https://www.scientificamerican.com/article/how-children-learn-words/

Nagy, W. E. \& Anderson, R. (1984). The number of words in printed school English. Reading Research Quarterly, 19(3), 304-330. https://doi.org/10.2307/747823

Plag, I. (2003). Word-formation in English. Cambridge University.

Ratih, E., \& Gusdian, R. I. (2018). Word formation processes in English new words of Oxford English dictionary (OED) online. Celtic: A Journal of Culture, English Language Teaching, Literature and Linguistics, 5(2), 24-35. http://202.52.52.22/index.php/celtic/article/view/7617

Rodriguez-Puente, P. (2020). Register Variation in Word-formation Processes. International Journal of English Studies, 20(2), 145-167. https://doi.org/10.6018/ijes.364261

Shchuklina, T., Mardieva, L., \& Alyokhina, T. (2016). Teaching Russian language: The role of word formation. The European Proceedings of Social and Behavioural Sciences, 12, 190-196. http://dx.doi.org/10.15405/epsbs.2016.07.31

Sterling, C. (1982). The psychological productivity of inflectional and derivational morphemes. In: D. Rogers, \& J. Slobada, (Eds.). The acquisition of symbolic skills. Plenum.

Stanners, R., Neisser, J., Hernon, W., \& Hall, R. (1979). Memory representation for morphologically related words. Journal of Verbal Learning and Verbal Behaviour, 21, 704-721. https://doi.org/10.1016/S0022-5371(79)90219-6

Stump, G. T. (2001). Inflection. In: A. Spencer, \& A. M. Zwicky, (Eds.). The Handbook of Morphology (pp. 13-43). John Wiley.

Tahaineh, Y. (2012). The awareness of the English word-formation mechanisms is a necessity to make an autonomous L2 learner in EFL context. Journal of Language Teaching and Research, 3, 1105-1113. https://doi.org/10.4304/jltr.3.6.1105-1113 
Taft, M., \& Forster. K. (1975). Lexical storage and retrieval of prefixed words. Journal of Verbal Learning and Verbal Behaviour, 14(6), 638-647. https://doi.org/10.1016/S0022-5371(75)80051-X

Verhoeven, L., and Carlisle J. F. (2006). Introduction to the special issue: Morphology in word identification and word spelling. Reading and Writing, 19(7), 643-650. https://doi.org/10.1007/s11145-006 9010-5

Vidra, J. \& Zabokrtsk'y, Z. (2017). Online software components for accessing derivational networks. In Proceedings of the Workshop on Resources and Tools for Derivational Morphology

(129-139). https://www.academia.edu/34790682/Proceedings_of_the_Workshop_on_Resource s and Tools for_Derivational_Morphology DeriMo

Yule, G. (2014). The study of language $\left(5^{\text {th }}\right.$ ed.). Cambridge University.

Zhang, D. (2017). Derivational morphology in reading comprehension of Chinese-speaking learners of English: A longitudinal structural equation modelling study. Applied Linguistics, 38(6), 871-895. https://doi.org/10.1093/applin/amv072 


\section{Appendix: The Proficiency Test about English Derivational Morphemes}

A) Make adjectives from the following words
1) Profession
2) Beauty
4) Magnet
5) Create
7) Love
8) Danger
10) Passion
11) Wood
3) Wound
6) Philosophy
9) Noise

B) Make nouns from the following words
1) Declare
2) Pregnant
4) Urgent
5) Permanent
7) Develop
8) Kind
3) Clear
6) Electric

C) Make verbs from the following words
1) Active
2) Strength
4) Hospital
5) Danger

3) Clear

D) Make adverbs from the following words

1) Careful

2) East

E) Make/select nouns from the following words
1) Block:
a) Blockage
b) Blockment
c) Blocked
d) Blockness
2) Pay:
a) Payness
b) Payable
c) Payee
d) Paytion
3) Conduct:
a) Condoctor
b) Conductment
c) Conductness
d)Conductfull
4) Write:
a) Writs
b) Writer
c) Writeful
d) Writeness
5) Teenage:
a) Teenaging
b) Teenageness
c) Teenaging
d) Teenage
6) The female lion is:
a) Lioness
b) Tiger
c) Cheetah
d) Zebra
7) A small kitchen is called:
a) Drawing room
b) Kitchenette
c) Dining room
d) Bed room
8) The period in your life when you were a child is called
a) Childness
b) Childment
c) Childhood
d) Childship

9) The sports or activity of climbing a mountain is called:
a) Mountaineering
b) Mounteneer
c) Mountaineerment
d) Mountaineeness

10) The belief in extreme measures is called
a) Extremering
b) Extremism
c) Exteremful
d) Exteremness

11) The inhabitants/people of China are called

12) The inhabitants/people of Brazil are called

13) A person who is expert in dentistry is called

14) A Diseases that can be cured is called
a) Cured
b) Curable
c) Curness
d) Cureful

15) Only thinking about one's self and not about other people need or want is attitude
a) Egocentric
b) Egoer
c) Egoist
d) Egotype

16) A person who is fooled by others is called
a) Fooled
b) Folly
c) Foolishness
d) Foolish

17) A person who behaves innocently like a child is called
a) Childlike
b) Childish
c) Childful
d) Childed

18) The opposite of useful is

19) A thing which does not let water through to be damaged is

20) The second caption of a team is called

21) An organism having one cell is called

22) A cycle having three wheels is called
a) Tricycle
b) Pentacycle
c) Monocycle
d) Bicycle

23) The sound higher than human can hear is called
a) Infrasound
b) Ultrasound
c) Intrasound
d) Extrsound 
24) Different from the original form is called

$\begin{array}{cc}\text { a) Extrascribe } & \text { b) Infrascribe } \\ \text { 25) Between two cultures is } & \text { and within a culture is }\end{array}$
b) Intraculture
c) Monoculture
d) Biculture

26) A very large shop is called

c) Ultrtrancribe

d)Transcribe
a) Megastore
b) Misrostore
c) Ultrastore
d) Infrastore

27) The study of the smallest organisms is called

28) Midterm means

29) one milligram is equal to grams

30) A very small than usual is called
a) Mingram
b) Miniature
c) Miniletter
d) Maximum

31) A word having one syllable is called

32) A word containing syllables is called

33) The things of later part of the stone age are called
a) Newlithic
b) Neolithic

34) Animals like human being eating all types of food like plants and other animals are called
a) Omnivorous
b) Herbivores
c) Carnivorous game.

35) Badminton is indoor game while cricket is an

36) The custom of having more than one wife is called

37) Another term for 'after the war' is

38) To use another name instead of the real name is called

39) The study of how mind processes and produces language is called

40) The term for 'gaining something again' is

41) The match before the final is called

42) A person who studies sociology is called

43) A smaller committee from a main committee is called

44) A country like America having greater influence and resources in the world is called

45) The instrument used for seeing distant things is called

F) What are the bound morphemes in the following words and their possible meaning?
1) Atypical
4) Autobiography
2) Antedate
7) Co-author
5) Bicycle
10) E-book
8) Counter-attack
13) Ex-husband
11) Ecosystem
14) Extra-thin
16) Geopolitical

3) Archbishop

6) Centimeter

9) Cyber link

12) Euro election

15) Forefather

G) Make negative from the following words
1) Finite
2) Possible
3) Literate
4) Rational
5) Well treated
6) Honest
9) Consciously
7) Forestation
10) Overestimate
5) Qualify
12) Native
15) Bibliophile
13) Underestimate
16) Hydrophobia
8) Clockwise
11) Guide
14) Anti-American
17) Kingship

\section{Notes:}

1 The compound word sometimes is a combination of two free morphemes (words) having no bound morpheme (derivational morpheme)

2 Sometimes, there can be one derivational morpheme deriving more than one lexical category, for example, the derivational morpheme 'mis' can derive a new verb or new noun as in misjudge and misuse. These two uses of derivational morpheme 'mis' are investigated separately in the present study. 